\title{
Diltiazem potentiation of doxorubicin cytotoxicity and cellular uptake in human breast cancer cells
}

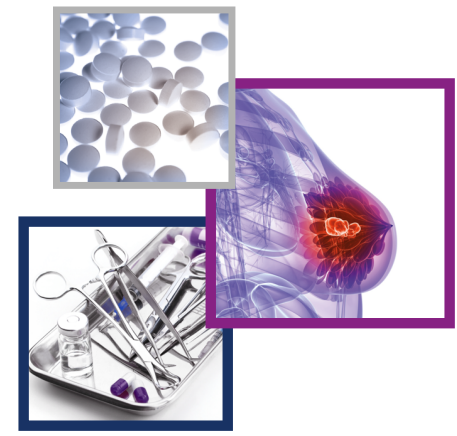

\author{
Hamdan S Al-malky*,1 (D), Zoheir A Damanhouri', Jumana Y Al Aama², Ali A Al \\ Qahtani ${ }^{1}$, Wafaa S Ramadan ${ }^{1,3}$, Huda M AlKreathy ${ }^{1}$, Sameer E Al Harthi ${ }^{1}$ \& \\ Abdel-Moneim M Osman ${ }^{1,4}$ \\ ${ }^{1}$ Department of Pharmacology, Faculty of Medicine, King Abdulaziz University, Saudi Arabia \\ ${ }^{2}$ Department of Genetics, Faculty of Medicine, King Abdulaziz University, Saudi Arabia \\ ${ }^{3}$ Department of Anatomy, Faculty of Medicine, Ain Shams University, Egypt \\ ${ }^{4}$ Pharmacology Unit, National Cancer Institute, Cairo University, Egypt \\ *Author for correspondence: hamdan27@hotmail.com
}

\begin{abstract}
Aim: Breast cancer is the most common cancer among Arab women and also around the world. Chronic cardiotoxicity and multidrug resistance are potential limiting factors of doxorubicin (DOX), a known anthracycline antibiotic. Materials \& methods: DOX cytotoxicity was evaluated by the sulforhodamine method. DOX cellular uptake, detection of P-glycoprotein activity and the photomicrograph of MCF-7 cells were also determined. Results: Diltiazem (DIL) treatment improved DOX cytotoxic activity and increased the cellular uptake of DOX significantly and aggregation of rhodamine 123, reflecting inhibition of P-glycoprotein pump. Cytopathological investigation of MCF-7 cells revealed marked cytotoxic activity of DOX in the presence of DIL. Conclusion: DIL treatment enhanced DOX cytotoxic effect and reduced multidrug resistance, which increased the drug accumulation intracellularly.
\end{abstract}

First draft submitted: 8 August 2019; Accepted for publication: 1 November 2019; Published online: 10 January 2020

Keywords: activity enhancement $\bullet$ diltiazem $\bullet$ doxorubicin $\bullet$ MCF-7 cells $\bullet$ multidrug resistance

Breast cancer is the most common cancer among Arab women and in women around the world. This cancer is also prevalent among young age women in western countries [1]. The anthracycline chemotherapy drug doxorubicin (DOX) has been considered as the most effective anticancer drug for the treatment of breast malignancy [2]. However, DOX causes chronic cardiotoxicity by intercalation between DNA base pairs on the double helix and degrading topoisomerase II, which is the major limiting factor in the use of DOX [3].

In addition, various other forms of cancer are unresponsive against DOX and those that were responding efficiently, ultimately become resistant causing a major threat to the treatment of breast cancer. Furthermore, overexpression of P-glycoprotein (P-gp) has been shown to prevent the entry of DOX molecules into murine breast cancer cells (4T1-R), hence causing DOX chemoresistance [4].

In many studies, P-gp expression has been shown to be associated strongly with resistance to drug treatment. These studies reported that the therapeutic failure in addition to relapse may be a result of an increasing degree of P-gp expression, either intrinsic or acquired [5]. Through studying the function of P-gp in resistance to chemotherapy, several attempts have been implicated that inhibit the function of P-gp, which enhances the efficacy of chemotherapeutic agents through increasing their concentrations. These studies also confirmed that combination remedy could be utilized as an approach to defeat multidrug resistance (MDR) [6,7].

This study investigated several approaches to overcome the side effects and resistance related to the use of such drug. Searching for a natural or synthetic alternative with anticancer or chemopreventive properties that can be used in combination with DOX was one of the major objectives.

Based on our previous work on potentiating effect of diltiazem (DIL) on DOX activity in an experimental tumor [8], we directed this study to further investigate the DIL-DOX interaction on human breast cell lines and the possible mechanism of this interaction. We also recently investigated the underlying molecular mechanisms of

Future Medicine 
DIL-induced enhancement in the cytotoxic activity of DOX by measuring the expression of genes responsible for drug resistance, apoptosis induction and cell cycle disturbance [9].

Therefore, this study completed many branches for our previous work and was directed to explore whether the calcium channel blocker DIL could improve the cytotoxicity of DOX against the growth of human breast cancer cells (MCF-7 cell line). The current study investigated cytotoxic P-gp activity of DOX, its cellular uptake in cancer cells and the activity of P-gp pump in presence and absence of DIL.

\section{Materials \& methods}

Drugs \& chemicals

DOX, DIL, SulfoRhodamine-B (SRB), dimethylsulfoxide 99.9\% (DMSO), Triton (X-100), AO A6014 and trypan blue powder were purchased from Sigma-Aldrich Co. (MO, USA), while Verapamil was purchased from Abbott (IL, USA). Fetal bovine serum, Dulbecco's Modified Eagle Medium (DMEM), Trypsin-EDTA (0.05\%) and phosphate-buffered saline (PBS, pH 7.4) were purchased from Thermo Fisher Scientific Inc. (MA, USA).

\section{Cells \& cell cultures}

The MCF-7 cell line used in this study was provided by the National Cancer Institute (Cairo University, Egypt). The adherent cells were grown as a single layer in the DMEM with penicillin $(100 \mathrm{IU} / \mathrm{ml})$, streptomycin $(100 \mu \mathrm{g} / \mathrm{ml})$ and $10 \%$ fetal bovine serum supplementations. Furthermore, these cells were cultured at $37^{\circ} \mathrm{C}$ in a humidified $5 \%$ $\mathrm{CO}_{2}$ atmosphere and were subcultured every $4-5$ days.

\section{Assessment of cytotoxicity}

Based on the description by Skehan et al., the SRB method was used to determine the cytotoxicity [10]. Cells were seeded in 96-well microtiter plates at a concentration of $40 \times 10^{3}$ cells/well in DMEM and after $24 \mathrm{~h}$, they were incubated in a $\mathrm{CO}_{2}$ incubator with increasing concentrations of DOX and DIL simultaneously for $48 \mathrm{~h}$. After $48 \mathrm{~h}$, $50 \%$ cold trichloroacetic acid was added to the cells for fixation at $4^{\circ} \mathrm{C}$ for $1 \mathrm{~h}$. The supernatant was then removed and the plates were washed five-times using distilled water. The plates were then air dried and stained for $30 \mathrm{~min}$ at room temperature with $0.4 \%$ SRB dissolved in $1 \%$ acetic acid. The unbound dye was then removed by washing with $1 \%$ acetic acid five-times and was air dried. However, the bound stain was solubilized with $100 \mu \mathrm{l} /$ well $10 \mathrm{mM}$ Tris base ( $\mathrm{pH} 10.5$ ) for $10 \mathrm{~min}$. The optical density was read under the ELx808 absorbance microplate reader (BioTek, VR, USA) at 490-530 nm.

Surviving fraction $=$ Optical density of treated cells/optical density of control cells

$\mathrm{IC}_{50}$ (the concentration of DOX necessary to produce $50 \%$ inhibition of cell growth) was calculated from linear regression equation of the survival fraction curve.

$$
\mathrm{Y}=\mathrm{mX}+\mathrm{b}
$$

where $\mathrm{Y}=0.5$ (the surviving fraction when there is a $50 \%$ inhibition of cell growth), $\mathrm{m}=$ the slope, $\mathrm{X}=$ dose of DOX induces $50 \%$ inhibition and $\mathrm{b}=$ the $y$-intercept.

\section{DOX cellular uptake}

The measurement of cellular DOX content was done using a spectrofluorometer based on the Kitagawa et al. method [11]. Cells were seeded in six-well plates at cell density $6-8 \times 10^{5}$ cells/well in DMEM and were then allowed to attach for $24 \mathrm{~h}$, followed by treatment with DOX concentrations $(0.25$ and $1 \mu \mathrm{g} / \mathrm{ml})$ alone or with DIL $20 \mu \mathrm{g} / \mathrm{ml}$ for $48 \mathrm{~h}$. After trypsinization of the cells, pellets were washed once with PBS, then resuspended $\left(1 \times 10^{6}\right.$ cells $)$ in $1 \mathrm{ml}$ of DMSO. The DMSO cell suspensions were centrifuged at $5000 \mathrm{rpm}$ for $20 \mathrm{~min}$ and the clear supernatants were collected for the assay. The clear supernatant was measured by a spectrofluorometery (Synergy HT; BioTek) at excitation of an emission wavelength ex $=496 \mathrm{~nm}$ and em $=592 \mathrm{~nm}$, respectively, for determination of DOX concentration.

\section{Detection of P-gp activity using rhodamine 123}

Mechanism of P-gp in MCF-7 cell line was determined using the Ludescher et al. method [12] based on the fluorescent properties of rhodamine 123 (Rho 123), transported through the membrane efflux pump P-gp. Flow cytometric assay was used to analyze the function of MDR in breast cancer cells, which enabled demonstration of 
significant differences in Rho 123 efflux and further aggregation inside cells. MCF-7 cells were seeded in six-well plates at density of $1 \times 10^{5}-10^{6}$ cells/well in DMEM. These cells were then cultured in a $\mathrm{CO}_{2}$ incubator for $24 \mathrm{~h}$ before treatment. The cells were stained with $1 \mu \mathrm{l} / \mathrm{ml}$ of Rho 123 and kept in a dark area for $30 \mathrm{~min}$ to $1 \mathrm{~h}$. After that, the cells were treated with DOX concentrations $(0.25$ and $1 \mu \mathrm{g} / \mathrm{ml})$ alone or with DIL $20 \mu \mathrm{g} / \mathrm{ml}$ for $1 \mathrm{~h}$. The medium was then removed, and cells were harvested with trypsin/EDTA. Following trypsinization, cells were washed with PBS, centrifuged and then the supernatant was discarded. The intracellular Rho 123 concentration was determined against a standard curve following the cell lysis with $2 \%(\mathrm{v} / \mathrm{v})$ Triton X-100 by spectrofluorometery (Synergy HT; BioTek).

\section{Fluorescence microscopic analysis of apoptosis}

A stock solution of acridine orange (AO) Sigma A6014 (MO, USA; $1 \mathrm{mg} / \mathrm{ml}$ ) was prepared according to manufacture protocol. The use of AO alone has been previously described as an inexpensive method to study lysosomal vacuolation, autophagy and apoptosis [13]. AO can penetrate the cell membrane and emits orange fluorescence on binding to RNA and green fluorescence on binding to DNA. This conduct varies as it binds to live, apoptotic or fixed permeabilized cells [14]. It has been confirmed that AO, because of green emission related to DNA alteration, and without the combination with another stain, can differentiate between different mechanisms of cellular death: apoptosis and necrosis [15]. In a recent study, Zhao et al. documented that AO staining is an efficient method to evaluate the cell apoptosis of zebrafish embryos [16].

This solution was aliquoted and stored at $4^{\circ} \mathrm{C}$ in the dark. With the dilution of the stock solution in PBS $(1 \mu \mathrm{g} / \mathrm{ml})$, a working solution was prepared and the cells were then seeded in the 12-well plates at a density of $5 \times 10^{4}$ cells per well, followed by overnight incubation under a $\mathrm{CO}_{2}$ incubator. Subsequently, the cells were then exposed to different concentrations of DOX $(0.25$ and $1 \mu \mathrm{g} / \mathrm{ml})$ alone or with DIL $20 \mu \mathrm{g} / \mathrm{ml}$, followed by 24-h incubation. The cells were harvested by trypsin and centrifuged at $700 \times \mathrm{g}$. After that, $20 \mu \mathrm{l}$ of $\mathrm{AO}$ was added to the cell plaque. The stock solution of dyes was then directly added to the culture media and before the imaging, the cells were incubated with the dye for 5-15 min at room temperature and the cells viewed under a fluorescence microscope (Moticam Pro 2828; $\mathrm{AO} \times 400$ )

\section{Nuclear cytoplasmic structural study}

Giemsa stain (GS) was used to study the structural alterations in the cells under the effect of different concentrations of medication and the experiment followed the specified protocol (Procedure no.: GS-10 Sigma). The cells were arranged for staining by removing the media, washing each well two-times with PBS and fixing the cells with absolute methanol as a monolayer for $5 \mathrm{~min}$. After that, the methanol was removed and the plate was air-dried. The cells were then stained with $1 \mathrm{ml}$ of a 1:20 dilution of modified Giemsa reagent in PBS. At room temperature, the plate was incubated for $1 \mathrm{~h}$, rinsed extensively with distilled water and air-dried. Slides were examined under light microscope (Olympus light microscope; BX51TF-Japan) and photographed with GS × 200 [17].

\section{Results}

\section{Effect of DIL treatment on the cytotoxicity of DOX}

The addition of DIL to DOX demonstrated a remarkable decline in surviving fraction values in comparison to with DOX alone. Also, as the concentration of DOX increased, the surviving fraction values decreased in a gradual way from 0.84 to 0.23 and from 0.79 to 0.17 for cells treated with $0.0156-1 \mu \mathrm{g} / \mathrm{ml}$ DOX simultaneously with DIL 10 and $20 \mu \mathrm{g} / \mathrm{ml}$, respectively (Figure 1). Cytotoxicity was shown as a percentage of surviving fraction of treated cells by untreated control cells. DOX treatment alone showed $\mathrm{IC}_{50}$ value of $0.89 \mu \mathrm{g} / \mathrm{ml}$ and when DIL was added at 10 and $20 \mu \mathrm{g} / \mathrm{ml}$, the $\mathrm{IC}_{50}$ of 0.28 and $0.21 \mu \mathrm{g} / \mathrm{ml}$, respectively, was observed (Table 1).

\section{Effect of DOX \&/or DIL on the P-gp efflux of the fluorescent dye}

As shown in Figure 2, MCF-7 cells poorly accumulated Rho 123 by showing P-gp-dependent efflux of the fluorescent dye. DOX 0.25 and $1 \mu \mathrm{g} / \mathrm{ml}$ increased dye accumulation in MCF-7 cells by 17 - and tenfold, respectively, compared with Rho $123(1 \mu \mathrm{g} / \mathrm{ml})$. The addition of DIL $(20 \mu \mathrm{g} / \mathrm{ml})$ to DOX either $0.25 \mathrm{or} 1 \mu \mathrm{g} / \mathrm{ml}$ restored and increased accumulation of dye significantly by 2.2- and 2.1-fold, respectively, compared with corresponding DOX treatment.

Table 2 and Figure 3 show DOX concentration $\left(\mu \mathrm{g} / 1 \times 10^{6}\right)$ in MCF-7 cells in presence and absence of DIL. 


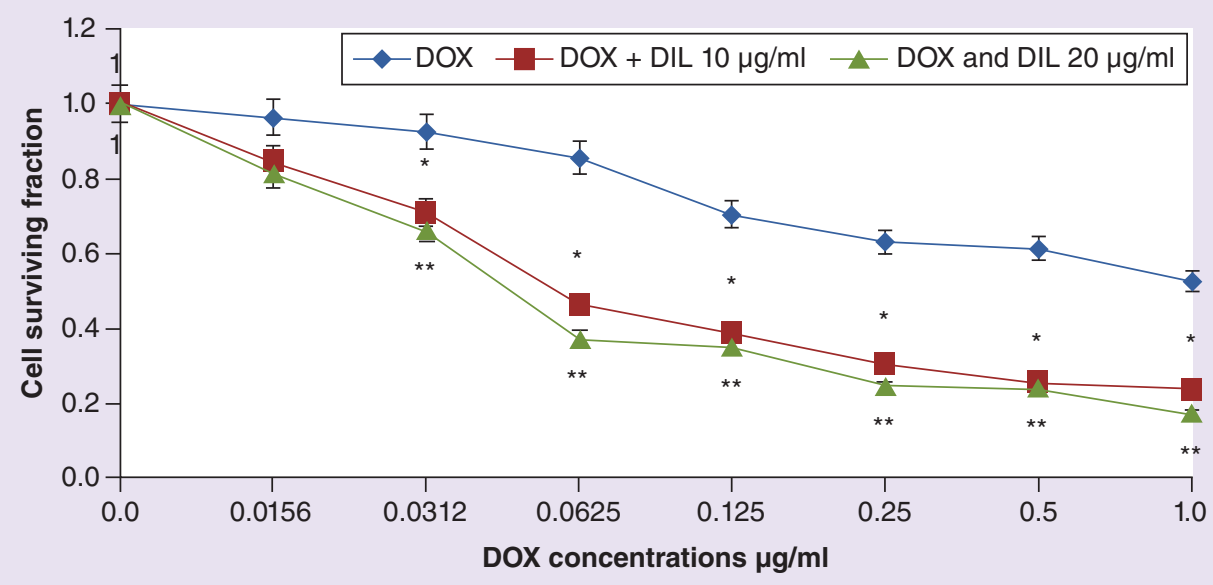

Figure 1. Effect of DOX and/or DIL (10 or $20 \mu \mathrm{g} / \mathrm{ml}$ ) treatment on the growth of MCF-7 cells. Data are expressed as mean \pm standard deviation of two experiments, each one in duplicate.

${ }^{*} \mathrm{p}=0.05$ after the addition of DIL $10 \mu \mathrm{g} / \mathrm{ml}$, compared with DOX alone

$* * \mathrm{p}=0.05$ after the addition of DIL $20 \mu \mathrm{g} / \mathrm{ml}$, compared with DOX alone.

DIL: Diltiazem; DOX: Doxorubicin.

\section{Table 1. Effect of doxorubicin and/or diltiazem treatment on the growth of MCF-7 cells (IC 50$)$.}

\begin{tabular}{ll} 
Treatment IC 50 & $(\mu \mathrm{g} / \mathrm{ml})$ \\
\hline DOX & $0.89 \pm 0.8$ \\
\hline DOX and DIL & $(10 \mu \mathrm{g} / \mathrm{ml}) 0.28 \pm 0.63^{\dagger}$ (supplied simultaneously) \\
\hline DOX and DIL & $(20 \mu \mathrm{g} / \mathrm{ml}) 0.21 \pm 0.35^{\dagger}, \ddagger$ (supplied simultaneously)
\end{tabular}

Data are expressed as mean \pm standard deviation of two experiments each one in duplicate

$\dagger$ Remarkably different from the DOX at p-value $<0.05$.

¥Insignificantly different between DIL either 10 or $20 \mu \mathrm{g} / \mathrm{ml}$.

DIL: Diltiazem; DOX: Doxorubicin; IC50: the concentration of DOX necessary to generate $50 \%$ inhibition in the growth of cells.

\section{Table 2. Effect of diltiazem treatment on doxorubicin cellular uptake in MCF-7 cells.}

\begin{tabular}{|ll}
\hline Treatment & DOX concentra \\
\hline DOX $0.25 \mu \mathrm{g} / \mathrm{ml}$ & $0.037 \pm 0.01^{\dagger}$ \\
\hline $\mathrm{DOX} 1 \mu \mathrm{g} / \mathrm{ml}$ & $0.144 \pm 0.13^{\ddagger}$ \\
\hline DOX $1 \mu \mathrm{gl} / \mathrm{ml}+\mathrm{DIL} 20 \mu \mathrm{g} / \mathrm{ml}$ & $0.113 \pm 0.01^{\dagger}$ \\
\hline
\end{tabular}

†The growing cells were treated with DOX and/or $20 \mu \mathrm{g} / \mathrm{ml}$ DIL for $48 \mathrm{~h}$. Cells washed once with phosphate-buffered saline and were harvested, counted and resuspended in $1 \mathrm{ml}$ of $20 \%$ DMSO. The DMSO cell suspensions were centrifuged and the clear supernatant was collected for the assay. Data are expressed as mean \pm standard deviation of the experiment $(n=2)$.

¥Significantly different from corresponding DOX at p-value $<0.05$

DIL: Diltiazem; DMSO: Dimethylsulfoxide; DOX: Doxorubicin.

DOX cellular concentration were 0.037 and $0.113\left(\mu \mathrm{g} / 1 \times 10^{6}\right)$ after respective treatment with $0.25 \mathrm{and} 1 \mu \mathrm{g} / \mathrm{ml}$ DOX. The addition of DIL at a dose of $20 \mu \mathrm{g} / \mathrm{ml}$ with DOX increased its concentration by 3.9- and 2.7-fold, respectively.

Fluorescence microscopic analysis of apoptosis \& nuclear cytoplasmic structural after DOX \&/or DIL treatment

Photomicrographs of MCF-7 breast cancer cells treated with DOX and/or DIL displayed a control with a confluent monolayer of typical spindle-shaped cells with well-defined outline and abundant cytoplasm (Figure 4A). Cells treated with DIL $20 \mu \mathrm{g} / \mathrm{ml}$ showed few shrunken cells that were markedly increased on treatment with DOX $0.25 \mu \mathrm{g} / \mathrm{ml}$ only few cells retained their shape (Figure 4B \& C). In addition, cells treated with higher dose of DOX 


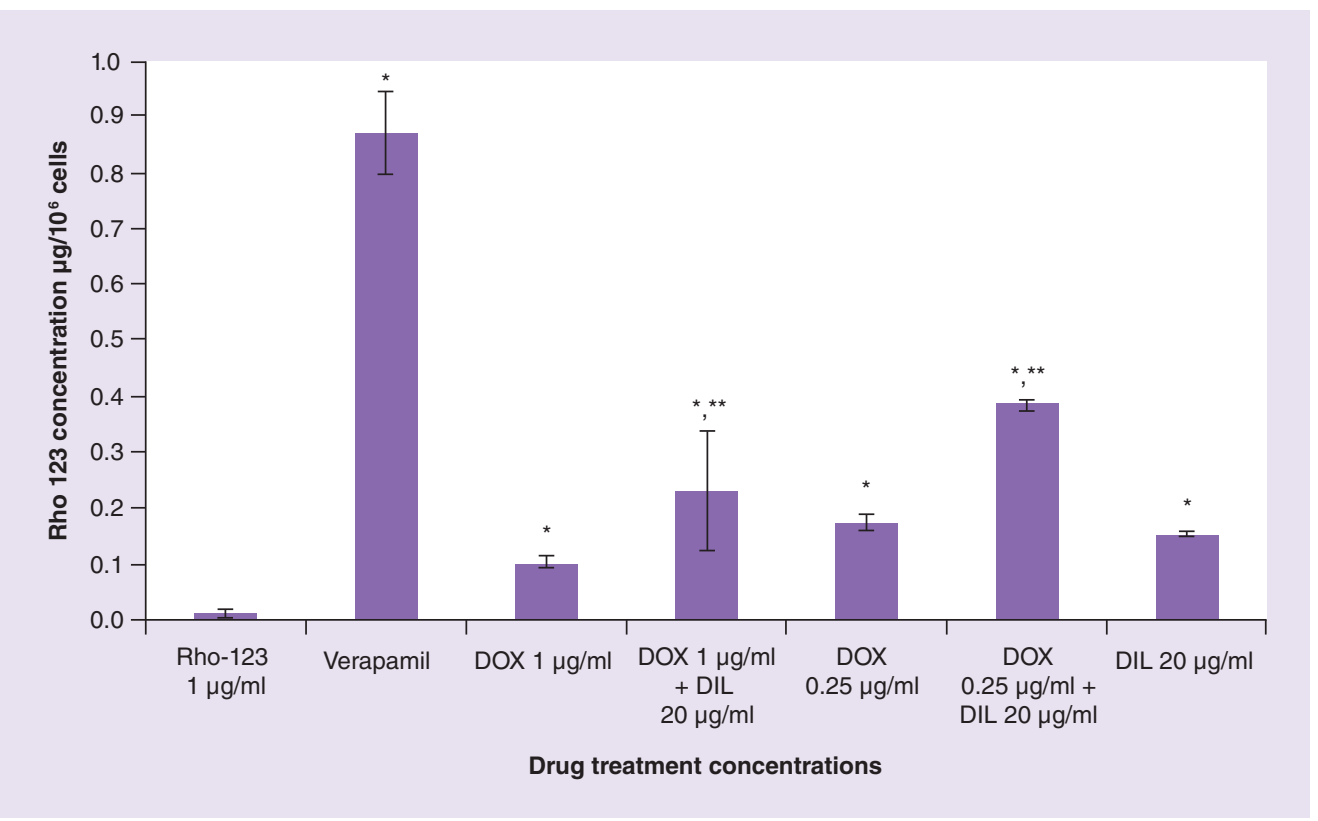

Figure 2. MCF-7 cells were exposed to $1 \mu \mathrm{l} / \mathrm{ml}$ rhodamine 123 for $30 \mathrm{~min}$ at $37^{\circ} \mathrm{C}$. Rho 123 accumulations were quantified by spectrofluorometry after washing. Data are expressed as ratio of fluorescent dye accumulation in MCF-7 cells with the means \pm standard deviation of two experiments each one in duplicate.

${ }^{*} \mathrm{p}<0.05$ compared with Rho 123.

**Compared with corresponding DOX.

DIL: Diltiazem; DOX: Doxorubicin; Rho 123: Rhodamine 123.

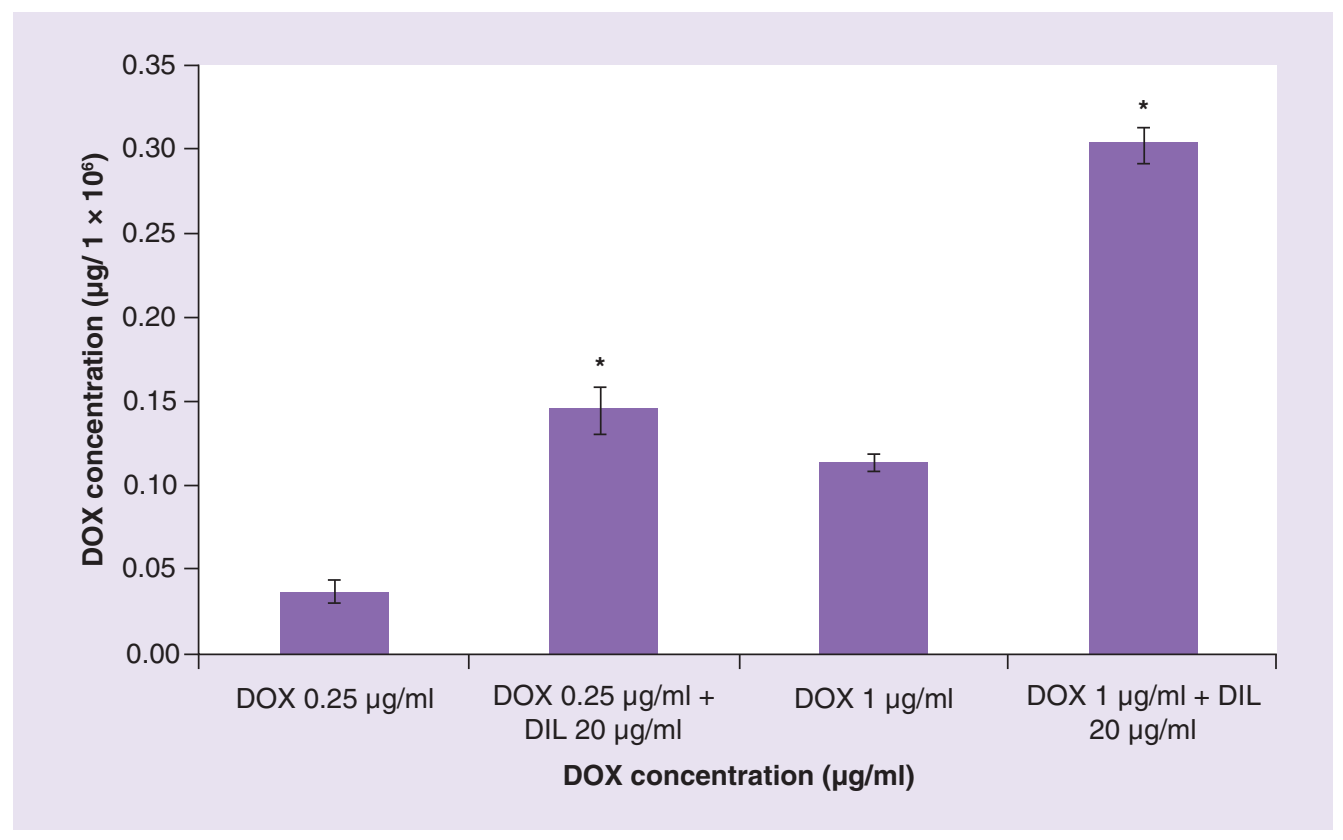

Figure 3. Effect of diltiazem treatment on doxorubicin cellular uptake in MCF-7 cells. Cells were treated with DOX and/or with $20 \mu \mathrm{g} / \mathrm{ml} \mathrm{DIL}$ for $48 \mathrm{~h}$, followed by washing with phosphate-buffered saline. The cells were then harvested, counted and resuspended in $1 \mathrm{ml}$ of dimethylsulfoxide. The dimethylsulfoxide cell suspensions were centrifuged and the clear supernatant was collected for the assay with the means \pm standard deviation of two experiments each one in duplicate.

${ }^{*} p<0.05$ compared with corresponding DOX.

DIL: Diltiazem; DOX: Doxorubicin. 


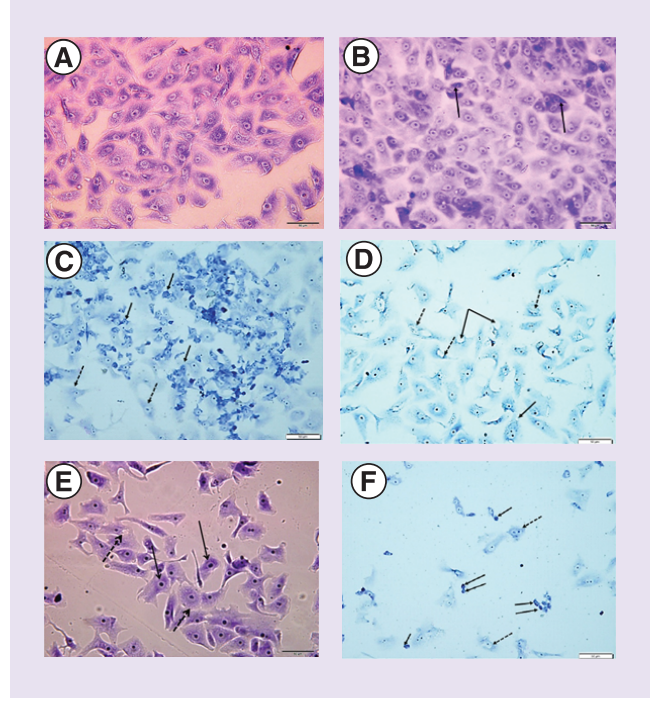

Figure 4. Photomicrographs of MCF-7 breast cancer cells. (A) Control. (B) Cells treated with DIL $20 \mu \mathrm{g} / \mathrm{ml}$. (C) Cells treated with DOX $0.25 \mu \mathrm{g} / \mathrm{ml}$. (D) Cells treated with DOX $0.25 \mu \mathrm{g} / \mathrm{ml}+$ DIL $20 \mu \mathrm{g} / \mathrm{ml}$. (E) Cells treated with DOX $1 \mu \mathrm{g} / \mathrm{ml}$. (F) Cells treated with DOX $1 \mu \mathrm{g} / \mathrm{ml}+\mathrm{DIL} 20 \mu \mathrm{g} / \mathrm{ml}(\mathrm{GS} \times 400)$. DIL: Diltiazem; DOX: Doxorubicin; GS: Giemsa stain.

$1 \mu \mathrm{g} / \mathrm{ml}$ revealed condensed nuclear chromatin and perinuclear halo and some cells showed cytoplasmic vacuoles (Figure 4E). The addition of DIL to DOX induced multiple cytoplasmic vacuoles (more enhancements toward apoptosis) of different sizes and more nuclear fragmentations were also noted in the field (Figure 4D \& F).

Figure 5 showed cells stained with vital stain (AO) and visualized by florescent microscope. In the control group, cells revealed green intact nuclei of viable cells (arrows). In case of cells subjected to DIL $20 \mu \mathrm{g} / \mathrm{ml}$, some nuclei revealed dense green areas of chromatin condensation presenting early apoptosis (dashed arrows). The increase in these cells was DOX dose-dependent and on simultaneous use of DOX and DIL. DOX $1 \mu \mathrm{g} / \mathrm{ml}$ and DIL-treated cells demonstrated a reduced count in the field, with condensed chromatin.

\section{Discussion}

Our study was focused on investigating whether DIL (a calcium channel blocker [CCB]) can overcome the resistance to DOX therapy as well as enhancement of its cytotoxic effects against the growth of MCF-7 human breast cancer cell line. The idea of using CCBs with chemotherapy drugs for the treatment of cancer is supported by many literatures (e.g., vincristine and adriamycin), which results in enhanced cytotoxicity in multiple cell lines (e.g., glioma, prostate and lung) $[18,19]$.

In our results, DIL dose showed no direct cytotoxic activity against breast cancer cells by DIL alone, however, it improved the DOX uptake into the tumor cells. A good correlation was reported between the high cellular level of DOX in MCF-7 cells in presence of DIL and the increased in the cytotoxicity of DOX was observed by a decrease in $\mathrm{IC}_{50}$ (Figure $1 \&$ Table 1). In agreement with our result, Al-Shabanah et al. reported that the DIL potentiates DOX cytotoxicity and cellular uptake in Ehrlich ascites carcinoma cells in mice. They found that pretreatment with DIL increased the survival rate of Ehrlich ascites carcinoma-bearing mice [8]. In addition, Chiu et al. compared DIL and nifedipine with verapamil in their ability to reverse DOX resistance in A549/D16 human lung cancer cells lines [20]. These results indirectly agree with the work of Nguyen et al., where they found that concurrent treatment of DOX with calcium caused decline in cytotoxic effect of DOX [21]. MDR continues to be a major clinical obstacle to effective cancer chemotherapy. The hallmark of MDR is the expression of P-gp, which acts as a transmembrane drug exporter [22]. It plays a role in the development of drug resistance in several cancers including those of the lung, breast, prostate, ovarian cancers and myeloid leukemias as well as childhood neuroblastoma [23,24].

To examine the function of P-gp in altering the usefulness of the agents, we studied the effect of DOX and/or DIL on the P-gp efflux of the fluorescent dye. We used verapamil as a reference that inhibits the activity of P-gp [25]. A significant increase in accumulation of Rho 123 dye in MCF-7 cells has been observed after the addition of DIL to DOX by more than eightfold (Figure 2) indicating inhibition of P-gp efflux pump that leads to more accumulation of DOX with more cytotoxicity. These results have been further confirmed by the observed increase in DOX cellular uptake in MCF-7 cells after simultaneous treatment with DIL in a dose-dependent manner (Figure $3 \&$ Table 2). However, a low dose of DOX showed more accumulation of Rho 123 in MCF-7 cells than a high dose. This result is consistent with work of Riganti et al., where they found two repeated low doses of DOX is 

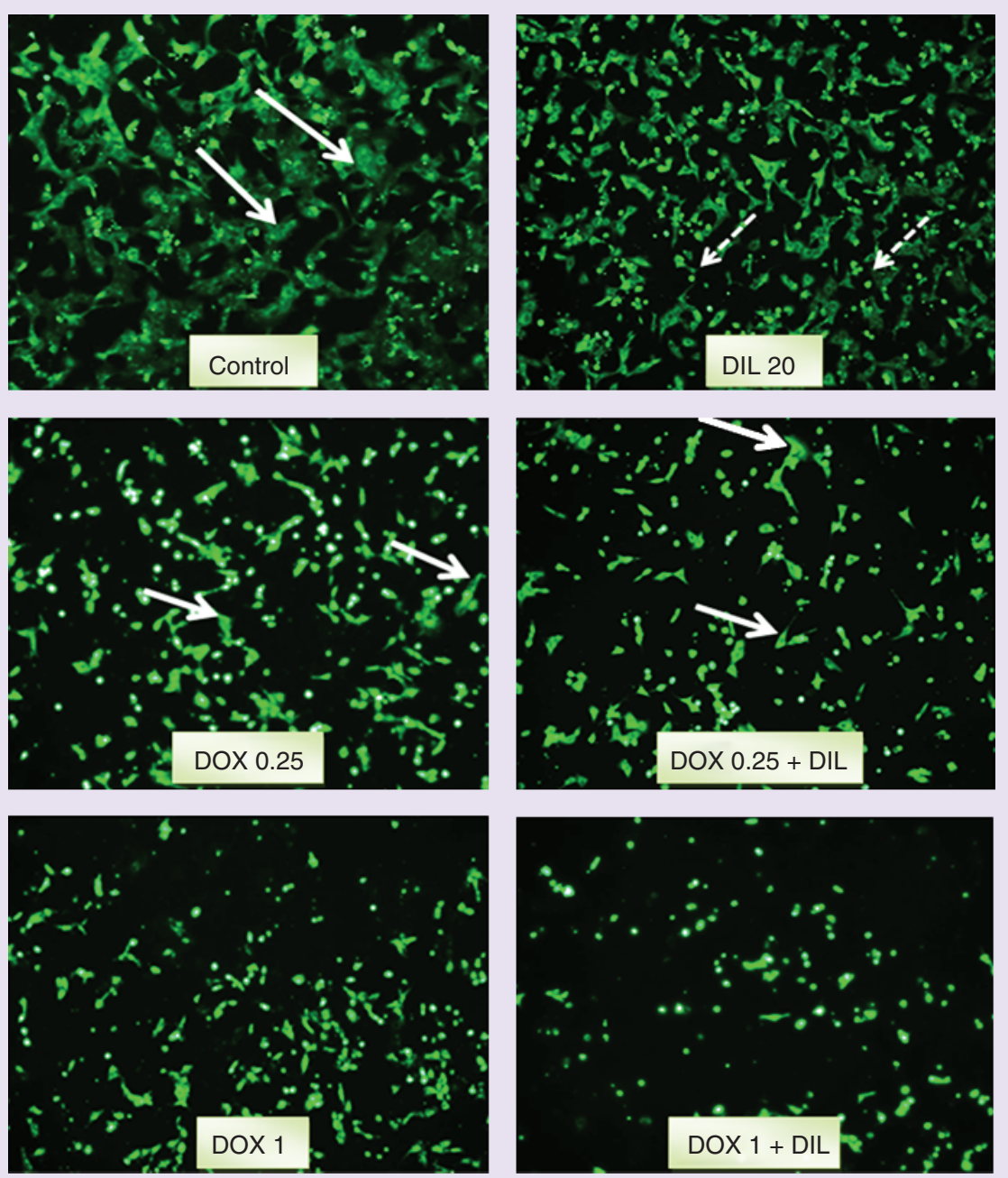

Figure 5. Photomicrographs of MCF-7 breast cancer cells stained with vital stain (acridine orange) and visualized by fluorescent microscope. In the control group, cells revealed green intact nuclei of viable cells (arrows). In case of cells subjected to DIL $20 \mu \mathrm{g} / \mathrm{ml}$, some nuclei revealed dense green areas of chromatin condensation presenting early apoptosis (dashed arrows). The DOX $1 \mu \mathrm{g} / \mathrm{ml}$ and DIL-treated cells showed few cells in the field, all of which revealed condensed chromatin (GS $\times 400)$.

DIL: Diltiazem; DOX: Doxorubicin.

more effective than a single high dose against tumors overexpressing P-gp [26]. They reported that the two repeated low-dose treatment reduced cell proliferation and increased the cleavage of caspase 3, suggesting that it activated the proapoptotic machinery in resistant cells. In addition, they showed a significant increase of intracellular ROS levels paralleled by typical signs of oxidative damages, such as a decrease in Gluthathione levels and increased lipid peroxidation. It has been reported that low doses of liposomal DOX produced greater clinical benefits in patients with breast metastatic cancers than standard chemotherapy protocols based on maximum tolerated doses [27].

In the present study, the increased DOX cellular uptake inside MCF-7 cells can be explained based on inhibition of P-gp and MDR. In many studies, the treatment with cytotoxic agents directly effects on MDR-1 promoter [28,29].

These agents lead to MDR-1/P-gp expression by transcriptional and translational activation. Moreover, chemosensitization of tumor cells is one of objectives for research to find an adjuvant therapy working via inhibition of P-gp, which results to increase the concentration of chemotherapeutic agents intracellularly [10,11].

Light microscopic study confirmed the biochemical data in MCF-7 cells, where a shrunken appearance of the cells with condensed nuclear chromatin after DOX treatment has been observed. In addition, a marked condensation of the nuclear chromatin and perinuclear halo were detected with some cells showing cytoplasmic vacuoles when 
DOX concentration was increased (Figure 4C \& E). After the addition of DIL, highly condensed nuclear fragments and a rim of cytoplasmic were scattered (Figure 4F).

These results may suggest that the combination treatment of DOX and DIL induces apoptosis of the MCF-7 cells in a time-dependent manner, which may lead to a reduced dose of chemotherapy and consequently reduced side effects. Hence, depending on the current results, it can be said that the DIL inhibits P-gp when it is provided in combination with DOX, followed by increase in the DOX cellular uptake. However, the exact reasons behind the cytotoxicity improvement by CCBs are unclear, because of the difficulty in assessing the relation of drug accumulation and cytotoxicity. This is because drug accumulation might not be the only factor that influences the cytotoxicity of chemotherapeutic agents. Studies are needed in which basic questions concerning tumor enhancement or suppression functions can be addressed using robust and clinically relevant cancer models.

Ikeda et al. reported that blockage of CCB-attenuated DOX induced cardiomyocyte apoptosis by suppression the intracellular $\mathrm{Ca}^{2+}$ abnormalities through suppression $\mathrm{Ca}^{2+} /$ calmodulin-dependent protein kinase II, which might be beneficial in DOX-induced cardiomyopathy. Therefore, together with present work, it seems interesting to use DIL, a CCB with DOX to increase its activity and decrease toxicity [30]. The use of these models to investigate DOX-induced cardiotoxicity will hopefully help to reduce the gap in basic research. Patient-based studies, other than those focused on preclinical models, may contribute toward the field. Until now, early detection of cardiotoxicity and mechanisms of pathophysiology have not been examined.

In summary, this study suggests the possible novel use of DIL to enhance the antitumor activity of DOX, allowing its dose and consequently the serious side effects, to be reduced.

\section{Conclusion}

CCB, DIL treatment enhanced DOX cytotoxic effect and reduced MDR. As such, increasing the drug accumulation inside cancer cells may predict a good chance to improve the cytotoxic activity of DOX. Such improvement may lead to a decrease in the dose and, consequentally, its side effects. This could result in improvements in the general performance of cancer patients and could limit the cost of treatment.

\section{Summary points}

- Doxorubicin (DOX) has been considered an effective drug against breast cancer, to which chronic cardiotoxicity and multidrug resistance are potential limiting factors.

- Resistance to chemotherapeutic drugs may be considered one of the more important reasons for cancer return, deterioration and metastasis.

- Investigating whether diltiazem can overcome the resistance to DOX therapy.

- Enhancement of DOX cytotoxic effects against the growth of MCF-7 human breast cancer cell line.

- Diltiazem could improve the cytotoxicity of DOX against the growth of human breast cancer cells (MCF-7 cell line).

- Increasing the drug accumulation inside cancer cells may predict a good chance to improve the cytotoxic activity of DOX.

\section{Author contributions}

AM Osman, HS Al-malky and AA Al-Qahtani shared the experimental work and WS Ramadan did cytopathological investigation, and others read and shared their interpretation of data and contributed in the writing of manuscript.

\section{Financial \& competing interests disclosure}

This project was funded by the King Abdul-Aziz City for Science and Technology under grants no. 1-18-03-009-0009. The authors therefore, acknowledge with thanks the King Abdulaziz City and financial support. The authors have no other relevant affiliations or financial involvement with any organization or entity with a financial interest in or financial conflict with the subject matter or materials discussed in the manuscript apart from those disclosed.

No writing assistance was utilized in the production of this manuscript. 


\section{Open access}

This work is licensed under the Attribution-NonCommercial-NoDerivatives 4.0 Unported License. To view a copy of this license, visit http://creativecommons.org/licenses/by-nc-nd/4.0/

\section{References}

Papers of special note have been highlighted as: $\bullet$ of interest; $\bullet \bullet$ of considerable interest

1. Najjar H, Easson A. Age at diagnosis of breast cancer in Arab nations. Int. J. Surg. 8(6), 448-452 (2010).

2. Weiss RB. The anthracyclines: will we ever find a better doxorubicin? Semin. Oncol. 19(6), 670-686 (1992).

3. Lefrak EA, Pitha J, Rosenheim S, Gottlieb JA. A clinicopathologic analysis of adriamycin cardiotoxicity. Cancer 32(2), 302-314 (1973).

- It explains the mechanism of doxorubicin cardiotoxicity, which is the major limiting factor in the use of the previous drug as chemotherapy agent.

4. McCarthy M, Auda G, Agrawal S et al. In vivo anticancer synergy mechanism of doxorubicin and verapamil combination treatment is impaired in BALB/c mice with metastatic breast cancer. Exp. Mol. Pathol. 97(1), 6-15 (2014).

5. Mechetner E, Kyshtoobayeva A, Zonis $S$ et al. Levels of multidrug resistance (MDR1) P-glycoprotein expression by human breast cancer correlate with in vitro resistance to taxol and doxorubicin. Clin. Cancer Res. 4(2), 389-398 (1998).

6. Ghanbari P, Mohseni M, Tabasinezhad M et al. Inhibition of survivin restores the sensitivity of breast cancer cells to docetaxel and vinblastine. Appl. Biochem. Biotechnol. 174(2), 667-681 (2014).

-• Discusses in some details approaches to defeat multidrug resistance (MDR), which is an essential part in chemotherapy resistance.

7. Samadi N, Ghanbari P, Mohseni M et al. Combination therapy increases the efficacy of docetaxel, vinblastine and tamoxifen in cancer cells. J. Cancer Res. Ther. 10(3), 715-721 (2014).

- Explains the function of P-glycoprotein (P-gp) that acts as an ATP-dependent drug efflux pump, reducing the intracellular accumulation of chemotherapeutic drugs.

8. Al-Shabanah OA, Osman AMM, Al-Harbi MM, Al-Bekairi AM, Al-Gharably NM, Aziz SA. Diltiazem potentiation of doxorubicin cytotoxicity and cellular uptake in Ehrlich ascites carcinoma cells. Chemotherapy 41(5), 368-377 (1995).

9. Hamdan SA, Osman AM, Damanhouri ZA et al. Modulation of doxorubicin-induced expression of the multidrug resistance gene in breast cancer cells by diltiazem and protection against cardiotoxicity in experimental animals. Cancer Cell Int. 19(1), 191 (2019).

10. Skehan P, Storeng R, Scudiero D et al. New colorimetric cytotoxicity assay for anticancer-drug screening. J. Natl Cancer Inst. 82(13), 1107-1112 (1990).

-• Explains the cytotoxicity assay.

11. Kitagawa S, Nabekura T, Kamiyama S. Inhibition of P-glycoprotein function by tea catechins in KB-C2 cells. J. Pharm. Pharmacol. 56(8), 1001-1015 (2004).

12. Ludescher $\mathrm{C}$, Thaler J, Drach D et al. Detection of activity of P-glycoprotein in human tumor samples using rhodamine 123. Br. J. Haematol. 82(1), 161-168 (1992).

- Explains the determination and detection of P-gp activity that is important to define MDR.

13. Fan C, Wang W, Zhao B, Zhang S, Miao J. Chloroauine inhibits cell growth and induces cell death in A549 lung cancer cells. Bioorg. Med. Chem. 14(9), 3218-3222 (2006).

14. Kusuzaki K, Matsubara T, Satonaka H et al. Intraoperative Photodynamic Surgery (iPDS) with acridine orange for musculoskeletal sarcomas. Cureus 6(9), e204 (2014).

15. Plemel JR, Caprariello AV, Keough MB et al. Unique spectral signatures of the nucleic acid dye acridine orange can distinguish cell death by apoptosis and necroptosis. J. Cell Biol. 216(4), 1163-1181 (2017).

16. Weichao Z, Nan H, Dexin D et al. Developmental toxicity and apoptosis in zebrafish embryos induced by low-dose $\gamma$-ray irradiation. Environ. Sci. Pollut. Res. Int. 26(4), 3869-3881 (2019).

17. Ho K, Yazan LS, Ismail N, Ismail M. Apoptosis and cell cycle arrest of human colorectal cancer cell line HT-29 induced by vanillin. Cancer Epidemiol. 33(2), 155-160 (2009).

18. Yohem KH, Clothier JL, Montague SL et al. Inhibition of tumor cell invasion by verapamil. Pigment Cell Res. 4(5-6), 225-233 (1991).

19. Jensen RL, Lee YS, Guijrati M, Origitano TC, Wurster RD, Reichman OH. Inhibition of in vitro meningioma proliferation after growth factor stimulation by calcium channel antagonists: part II-additional growth factors, growth factor receptor immunohistochemistry, and intracellular calcium measurements. Neurosurgery 37(5), 937-946 (1995).

20. Chiu LY, Ko JL, Lee YJ, Yang TY, Tee YT, Sheu GT. L-type calcium channel blockers reverse docetaxel and vincristine-induced multidrug resistance independent of ABCB1 expression in human lung cancer cell lines. Toxicol. Lett. 192(3), 408-418 (2010).

21. Nguyen TT, Lim YJ, Fan MH et al. Calcium modulation of doxorubicin cytotoxicity in yeast and human cells. Genes Cells 21(3), 226-240 (2016). 
22. Amin ML. P-glycoprotein inhibition for optimal drug delivery. Drug Target Insights 7, 27-34 (2013).

- Demonstrates the role of P-gp expression in MDR and development of drug resistance.

23. Munoz M, Henderson M, Haber M, Norris M. Role of the MRP1/ABCC1 multidrug transporter protein in cancer. IUBMB Life 59(12), 752-757 (2007).

24. Gottesman MM, Pastan IH. The role of multidrug resistance efflux pumps in cancer: revisiting a JNCI publication exploring expression of the MDR1 (P-glycoprotein) gene. J. Natl Cancer Inst. 107(9), djv222 (2015).

25. Karwatsky J, Lincoln MC, Georges E. A mechanism for P-glycoprotein-mediated apoptosis as revealed by verapamil hypersensitivity. Biochemistry 42(42), 12163-12173 (2003).

26. Riganti C, Gazzano E, Gulino GR, Volante M, Ghigo D, Kopecka J. Two repeated low doses of doxorubicin are more effective than a single high dose against tumors overexpressing P-glycoprotein. Cancer Lett. 360(2), 219-226 (2015).

27. Manso L, Valdiviezo N, Sepulveda J et al. Safety and efficacy of metronomic non-pegylated liposomal encapsulated doxorubicin in heavily pretreated advanced breast cancer patients. Clin. Transl. Oncol. 15(6), 467-471 (2013).

28. Kohno K, Sato SI, Takano H, Matsuo KI, Kuwano M. The direct activation of human multidrug resistance gene (MDR1) by anticancer agents. Biochem. Biophys. Res. Commun. 165(3), 1415-1421 (1989).

29. Chin KV, Chauhan SS, Pastan I, Gottesman MM. Regulation of mdr RNA levels in response to cytotoxic drugs in rodent cells. Cell Growth Differ. 1(18), 361-365 (1990).

30. Ikeda S, Matsushima S, Okabe $\mathrm{K}$ et al. Blockade of L-type $\mathrm{Ca}^{2+}$ channel attenuates doxorubicin-induced cardiomyopathy via suppression of CaMKII-NF-kB pathway. Sci. Rep. 9(1), 9850 (2019). 